\title{
Abordagem aos números decimais e suas operações: a importância de uma eficaz navegação entre representações*
}

Carlos Miguel Ribeiro

Universidade do Algarve

Correspondência:

Carlos Miguel Ribeiro

Universidade do Algarve

Escola Superior de Educação

e Comunicação

Campus da Penha

8000-117 Faro, Portugal

E-mail: cmribeiro@ualg.pt

\section{Resumo}

Este artigo foca alguns aspectos e ideias de tarefas a serem exploradas com os alunos relativamente à multiplicação de números decimais, discutindo o conhecimento matemático para o ensino subjacente à preparação e à aplicação de tais tarefas. Discutem-se algumas representações dessa multiplicação e a importância de um rico e fundamentado conhecimento matemático para o ensino como promotor de um conhecimento matemático com significado, por parte dos alunos, por via de uma eficaz navegação entre representações. A escolha das representações pretende, aqui, tornar também evidente o motivo pelo qual, ao multiplicar dois números decimais, o número de casas decimais do produto é a soma dos factores. 0 texto tem por base um trabalho colaborativo desenvolvido ao longo dos últimos anos com professores do $1^{\circ}$ ciclo do ensino básico (alunos com idade entre seis e nove anos), tendo como ponto de partida as discussões ocorridas ali, as reflexões subjacentes e as maiores dificuldades sentidas tanto pelos alunos, como pelos próprios professores. É de salientar que o facto de se abordarem conjuntamente representações dos números em decimais e fraccionários possibilita que os alunos se consciencializem de diferentes representações para um mesmo valor, o mesmo ocorrendo quando se utilizam diversas quantidades como unidades discretas, ou distintos tipos de unidades. Apenas se o professor for detentor de um sustentado conhecimento matemático para o ensino ele poderá recorrer a essas distintas representações de maneira construtiva e de modo a que tenham significado para os alunos.

\section{Palavras-chave}

Operações com decimais - Aprendizagens significativas - Processos construtivos - Primeiro ciclo. 


\section{Approaching decimal numbers and their operations: the importance of an effective navigation between representations*}

Carlos Miguel Ribeiro

University of Algarve

Correspondência:

Carlos Miguel Ribeiro

Universidade do Algarve

Escola Superior de Educação

e Comunicação

Campus da Penha

8000-117 Faro, Portugal

E-mail: cmribeiro@ualg.pt

\begin{abstract}
This article deals with aspects and ideas about tasks that can be explored with pupils related to the multiplication of decimal numbers, discussing the mathematics teaching knowledge underlying the preparation and conduction of these tasks. Some of the representations of this multiplication are discussed, as well as the importance of a rich and well-grounded mathematics teaching knowledge to promote meaningful mathematical knowledge for students through an efficient navigation between representations. The choice of representations is also intended here to make explicit the reason why, when multiplying two decimal numbers, the number of decimal places of the product is the sum of those of the factors. The text is based on a collaborative work developed during the last years with teachers of the $1^{\text {st }}$ cycle of basic education (pupils with ages between six and nine), having as its starting point the discussions that took place therein, and the underlying reflections and largest difficulties experienced both by pupils and by their teachers. It should be noted that approaching at the same time the representations of numbers in decimal and fractional forms allows pupils to become aware of different representations for the same value, the same happening when various quantities are used as discrete units, or when different types of units are employed. The teacher has to be in possession of well-founded mathematics teaching knowledge, so as to be able to make use of these distinct representations in a constructive way, and so that they will be meaningful for the pupils.
\end{abstract}

\section{Keywords}

Operations with decimals - Meaningful learning - Constructive processes - First cycle. 
Este texto baseia-se nas discussões e reflexões ocorridas num grupo de formação inserido no âmbito de um Programa de Formação Contínua em Matemática para Professores do $1^{\circ}$ e $2^{\circ}$ Ciclos do Ensino Básico ${ }^{1}$ (PFCM). Pretendo promover algumas reflexões que possam contribuir para uma mais profícua discussão sobre o conhecimento matemático para ensinar necessário aquando da abordagem às operações envolvendo números decimais (em particular, a multiplicação), e a importância do recurso a diferentes representações e de uma eficaz navegação entre estas.

O PFCM foi criado conjuntamente pelo Ministério da Educação e pelo Ministério da Ciência, Tecnologia e Ensino Superior portugueses, em 2006, e tem por objectivos primordiais promover o trabalho em rede entre escolas $\mathrm{e}$ agrupamentos $^{2}$ (centros educativos), em articulação com as instituições de formação inicial de professores; aprofundar o conhecimento matemático, didáctico e curricular dos professores de $1^{\circ}$ e $2^{\circ}$ ciclos; favorecer a realização de experiências de desenvolvimento curricular em matemática; fomentar uma atitude positiva dos professores relativamente à disciplina de matemática e às capacidades dos alunos; e criar dinâmicas de trabalho entre os professores, com vista a um investimento continuado no ensino da matemática (SERRAZINA et al., 2005; 2008).

Para conseguir atingir esses objectivos, existem sessões de formação conjunta (com periodicidade aproximadamente quinzenal), nas quais participam entre oito e dez professores de escolas vizinhas, sessões de acompanhamento individual em sala de aula e, no final do ano lectivo, é realizado um seminário (um dia) durante o qual os formandos são convidados

1- $01^{\circ}$ ciclo do ensino básico é respeitante aos quatro primeiros anos de escolaridade (alunos com idade compreendidas entre os seis e os nove anos, em condições normais), e nele existe, até ao momento, um único professor para todas as áreas curriculares.

2- De acordo com as orientações actuais, as escolas encontram-se agrupadas verticalmente; assim de um mesmo agrupamento - conjunto de escolas -, podem fazer parte escolas desde o pré-escolar até 0 ensino secundário. a apresentarem exemplos de boas práticas. 0 acompanhamento em sala de aula, efectuado pelo formador, é, pelo menos em teoria, ponto de partida para a reflexão nas sessões conjuntas, pretendendo ser, assim, foco de discussão de problemáticas efectivamente sentidas e vivenciadas pelos próprios intervenientes. A avaliação é baseada num portefólio reflexivo que cada formando tem de elaborar, contendo, necessariamente, pelo menos duas aulas comentadas. (Todas as aulas em que estive presente foram gravadas em vídeo, tendo os professores frequentemente referido, nas sessões conjuntas, a importância de sua posterior visualização para uma mais profícua reflexão sobre o que se passou, permitindo-lhes também notar/ver algumas coisas/situações que lhes tinham passado despercebidas em termos da relação entre sua actuação relativamente à forma como introduz, explora e conclui as tarefas e as aprendizagens/ dificuldades evidenciadas pelos alunos.)

Um dos tópicos discutidos em minhas sessões relaciona-se com os números decimais e fraccionários, e, posteriormente, com as operações. Esse é um dos temas fundamentais do ensino, principalmente nos primeiros anos, pois um claro entendimento a seu respeito proporciona o desenvolvimento de estruturas mentais importantes para futuras aprendizagens e, em particular, o raciocínio multiplicativo (STREEFLAND, 1991, 1997). Foram também discutidas diferentes interpretações que podem ser atribuídas aos decimais e fraccionários e às quatro operações que os envolvem. Essa discussão não se limitou apenas às operações em si (alguns dos diferentes algoritmos possíveis de se utilizar e uma análise de erros dos alunos), mas também tratou de possíveis distintas representações de uma mesma operação e da importância de uma perfeita navegação entre essas diferentes representações.

Neste texto, inicio por referir algumas notas teóricas relativas à importância das experiências como forma de facultar uma mais rica compreensão dos alunos em face dos números 
decimais e/ou fraccionários, e das operações envolvendo-os (excluindo a divisão), referindo também a importância das representações escolhidas e de uma eficaz navegação entre elas. Posteriormente, apresento alguns exemplos de actividades iniciais de introdução aos decimais e fraccionários, discutindo a importância de os alunos contactarem, desde logo, com diferentes recursos e representações de números, em concreto no caso da multiplicação de decimais, abordando também, nessa discussão, o conhecimento matemático para ensinar envolvido na selecção, exploração e navegação entre essas representações. Termino com algumas reflexões e implicações da utilização dos diferentes recursos e representações, bem como da importância/papel do conhecimento matemático para o ensino, necessário para que os professores levem a cabo, eficientemente, sua tarefa de ensinar.

\section{Algumas notas}

Ao consultarmos o Currículo Nacional do Ensino Básico Português (PORTUGAL, 2001) encontramos, de forma explícita, a pretensão de que os alunos adquiram tanto a aptidão para decidir sobre a razoabilidade de um resultado e para utilizar, consoante os casos, o cálculo mental, os algoritmos de papel e lápis ou os instrumentos tecnológicos, bem como a capacidade de utilizar a matemática, em combinação com outros saberes, na compreensão de situações da realidade, e o sentido crítico relativamente à utilização de procedimentos e resultados matemáticos. Mais concretamente, no domínio dos números e do cálculo, é referido que os alunos devem desenvolver competência matemática que lhes permita o reconhecimento e a utilização de diferentes formas de representar os conjuntos numéricos, assim como das propriedades das operações nesses conjuntos. Deverão também desenvolver uma sensibilidade para a ordem de grandeza de números, bem como a aptidão para estimar valores aproxima- dos de resultados de operações e decidir sobre a razoabilidade de resultados obtidos por qualquer processo de cálculo ou estimação.

No que se refere especificamente aos números inteiros e fraccionários e às quatro operações, é desejável, nesse nível de ensino ( $1^{\circ}$ ciclo), que os alunos adquiram a competência matemática que lhes permita uma clara compreensão do sistema de numeração de posição e do modo como este se relaciona com os algoritmos das quatro operações. Com esse fim em mente, devemos facultar aos alunos um vasto e diversificado conjunto de experiências e vivências que lhes permitam adquirir capacidades de reconhecimento dos números inteiros e decimais, da existência de diferentes formas de representação deles e de suas equivalências, bem como adquirir a aptidão de utilizar as propriedades das operações em situações concretas, particularmente quando facilitam a realização de cálculos.

Essas oportunidades devem surgir logo no momento de apresentação da unidade, pois quanto mais diversificadas forem as representações que os alunos possuem de um mesmo conceito, maior facilidade eles terão para trabalhá-lo em diferentes contextos. Sendo o primeiro conceito a ser abordado, o conceito de unidade tem um papel fundamental no estudo dos números e poderá, se não for devidamente explorado, ser uma fonte de dificuldade para os alunos quando trabalhados os números racionais (em particular, os decimais).

Esse tipo de exploração só será possível se o professor possuir um sólido e fundamentado conhecimento matemático para o ensino (CME). Essa expressão é aqui utilizada no sentido atribuído por Deborah Ball et al. (BALL; BASS, 2003; BALL; THAMES; PHELPS, 2008; HILL; ROWAN; BALL, 2005), referindo-se ao conhecimento necessário específico para ensinar, o qual é mais amplo do que qualquer outro tipo de conhecimento que permita simplesmente fornecer resposta às diversas situações matemáticas propostas. Nesse tipo de conhecimento, 
encontram-se incluídos o conhecer diversos tipos de representações para um mesmo conteúdo (o que, no caso concreto aqui abordado, refere-se a números decimais/fraccionários e suas operações) e o possuir o saber que permita uma eficaz navegação entre essas representações, de forma que seja possível enriquecer as estruturas e redes conceptuais dos alunos e permitir-lhes uma passagem e uma complementarização entre essas mesmas redes.

Para que os alunos adquiram uma competência matemática que lhes permita uma plena e clara compreensão do sistema de numeração de posição e do modo como este se relaciona com os algoritmos das quatro operações, é essencial que eles sejam confrontados com situações envolvendo diversas representações, devendo o professor ter em atenção não apenas a escolha dessas representações - e dos exemplos utilizados (ROWLAND, 2008) -, mas também o tipo de linguagem utilizada. Essas escolhas e a capacidade de navegar de forma segura e eficaz entre representações estão obviamente relacionadas também com os objectivos de aprendizagem que o professor persegue, pois a forma como explora essas representações e viaja entre elas poderá levar a diversos entendimentos distintos, por parte dos alunos, sobre o conteúdo que abordam, a matemática escolar e o tipo de utilização que se dá aos recursos (se são encarados meramente na perspectiva de serem atractivos ou associados a um objectivo matemático concreto e explícito).

\section{Alguns exemplos de actividades iniciais envolvendo decimais e fracções}

Quando pretendemos introduzir a noção de partes de uma unidade - representada tanto em números decimais, como em fraccionários -, devemos utilizar diferentes representações para a unidade, tanto contínuas (que se podem dividir indefinidamente), como discretas (conjunto de objectos contáveis). No caso das primeiras, podemos utilizar, por exemplo, um círculo, um rectângulo, a recta numérica etc.; para as segundas, 10 canetas, 20 crianças ou 30 cadeiras. Essa diversidade de representações e a percepção de sua equivalência enriquecerão, em grande medida, o conceito de número, uma vez que os alunos não ficam limitados a uma ou duas representações.

É importante, então, possibilitar que os alunos se consciencializem de que, por exemplo, uma décima de uma unidade corresponde sempre a uma das dez partes iguais em que a unidade foi dividida, independentemente de essa unidade ser contínua ou discreta e do facto de cada uma dessas décimas poder possuir aspectos visuais distintos.

Considerando, por exemplo, uma figura geométrica (unidade contínua), podemos dividi-la em dez partes de igual área, mas de diferentes formas, em que cada uma delas representa uma décima parte da figura (em área).

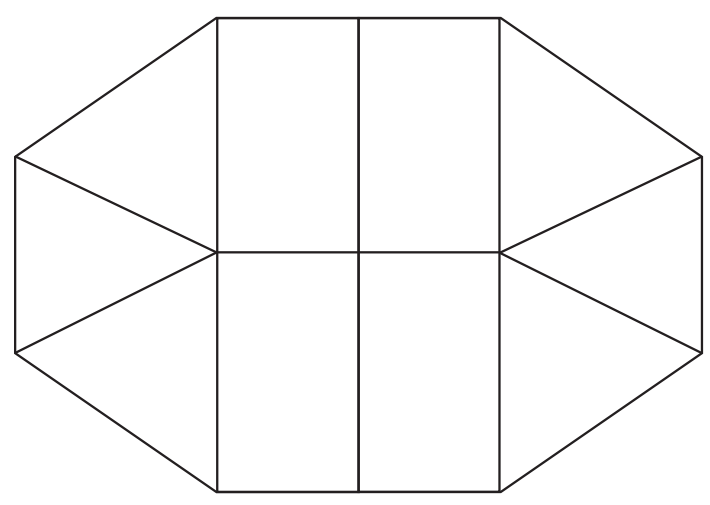

Figura 1 - Figura dividida em dez partes iguais em área.

No caso de a unidade ser discreta, a uma décima dessa unidade corresponderá cada uma das dez partes iguais em que essa unidade foi dividida, mas agora a igualdade das partes refere-se ao número de elementos de cada subconjunto formado. Assim, considerando um dos exemplos apresentados anteriormente, uma décima de um conjunto de 20 crianças será um 
conjunto de duas crianças. É evidente que, em cada um dos subconjuntos, as crianças serão diferentes, mas todos terão o mesmo número de crianças.

Outro contexto com o qual os alunos estão familiarizados e que pode/deve, por isso, ser significativamente utilizado e explorado na sala de aula, é o da utilização do dinheiro. Esse contexto é especialmente útil para a decomposição da unidade, representando um possível passo para a introdução dos decimais, pois, ao confrontarmos os alunos com problemas em que eles têm de, por exemplo, trocar uma moeda por outras, ou de determinar que parte equitativa de três euros (reais) de troco recebe cada um de cinco amigos, estamos a permitir que, para além de adquirirem competências sociais, adquiram também noções básicas de divisão equitativa de decimais. (Isso permite também a resolução de problemas com múltiplas soluções, o que, por si só, já enriquece as experiências dos alunos e sua visão da matemática escolar.)

Numa primeira fase, devem ser utilizados materiais manipuláveis de modo a facilitar a construção das noções e a perseguir os objectivos a que nos propomos, fornecendo problemas e tarefas que reflictam situações reais e próximas dos alunos, as quais podem ser abordadas em múltiplos contextos e integradas em diversos conteúdos - matemáticos e não só (BAROODY; COSLICK, 1998).

Um tipo de actividade que é, tradicionalmente, trabalhado com os alunos quando se pretende introduzir o conceito de décima é a divisão de um bolo/pizza ou chocolate em dez partes iguais, correspondendo cada uma dessas partes a uma décima. Com apenas essa experiência, os alunos frequentemente ficam demasiado apegados à décima como sendo uma fatia do bolo (não diferenciando, muitas vezes, o facto de o bolo poder estar, ou não, dividido em quantidades diferentes de dez), assumindo-a apenas como parte de uma unidade discreta. A fim de que esta não continue a ser uma realidade, é necessário e importante variar a unidade considerada, para que os alunos não desenvolvam a concepção de que uma décima tem sempre a forma de um sector circular, ou de um rectângulo, além de variar o número de partes em que a unidade se encontra dividida (e recorrer a diferentes tipos de unidades).

De modo a facultar aos alunos a oportunidade de irem, eles mesmos, construindo a noção de décima (de igual modo para os outros números racionais, e de um modo geral para todos os conteúdos - matemáticos ou não), é importante proporcionar-lhes tarefas e vivências que lhes permitam fazê-lo ao seu ritmo e com discussão entre os pares. Com essa comunicação das descobertas/relações, cria-se a oportunidade de serem eles próprios os avaliadores de suas aprendizagens e de compartirem a responsabilidade das aprendizagens do grupo (RIBEIR0, 2007). As tarefas, para que sejam efectivas promotoras de aprendizagem, devem, portanto, envolver situações problemáticas com significado para os alunos; ser a base para uma exploração e aplicação dos modelos; encorajar a realização de múltiplas abordagens e interpretações; dar prioridade à comunicação matemática; tornar necessária uma documentação dos resultados finais; e fazer da autoavaliação uma componente inerente à tarefa (LESH et al., 2000).

Um exemplo desse tipo de tarefa relacionada ao conceito de décima foi trabalhado numa sala de aula com alunos do $2^{\circ} \mathrm{e}$ do $3^{\circ}$ ano (alunos com idades de sete e oito anos), e tendo sido desenvolvida por todos os alunos. Após terem resolvido um problema envolvendo a divisão de uma unidade contínua em dez partes iguais (chocolate constituído por 20 cubinhos), a professora dividiu a turma em grupos de quatro elementos e entregou a cada grupo um saco transparente com alguns rebuçados. Após um momento de discussão entre os vários elementos de cada grupo, no sentido de determinar, por estimativa, o número de rebuçados que continha o 
saco, são distribuídos dez copos de plástico a cada grupo, efectuando os alunos uma divisão equitativa.

Professora: - Cada grupinho destes que está nos copos, o que é em relação ao saco todo? Alunos: - É uma décima.

Professora: - Quantos rebuçados tem cada copo?

Alunos: - Dois.

Professora: - Então, agora já sabemos ao certo o número de rebuçados que cada saco tinha!

Joana: - Pois é, cada copo tem dois, são dez copos por isso o saco tinha 20 rebuçados e os dois rebuçados representam uma décima.

Essa observação da Joana (que se verificou representativa da opinião do grupo) revela que os alunos compreenderam que a décima parte de determinada unidade pode ser uma quantidade diferente de um e não necessita ser uma parte de uma unidade contínua; dessa forma, eles não ficaram limitados a uma única representação da décima, mas enriqueceram e aumentaram, assim, também seus conhecimentos e competências matemáticas. Tal metodologia de resolução de problemas e de descoberta (em que se podem incluir também as actividades de investigação) conduz a aulas que requerem, da parte do professor, maiores empenho e envolvimento em relação às aulas de cariz mais expositivo, baseadas na utilização de fichas de trabalho ou exercícios do manual. Apesar dessa dificuldade acrescida, esse tipo de aula permite-nos encorajar os alunos a criar, explorar e explicar distintas representações que lhes sejam efectivamente úteis e que possuam significado para eles de modo que, tal como referem Helen Doerr e Lyn English (2006), não se limitem a considerar como suas as representações do professor.

Com o objectivo de enriquecer e fortalecer esse conhecimento dos números, para além da determinação das partes da unidade, ou seja, da desconstrução da unidade em partes iguais, devemos também disponibilizar aos alunos tarefas de construção de unidades. Uma dessas tarefas, que os professores do grupo do PFCM reportam como sendo bastante motivadora e matematicamente significativa para os alunos, é a de, considerando determinada parte da unidade, pedir-lhes para construírem a unidade $^{3}$.

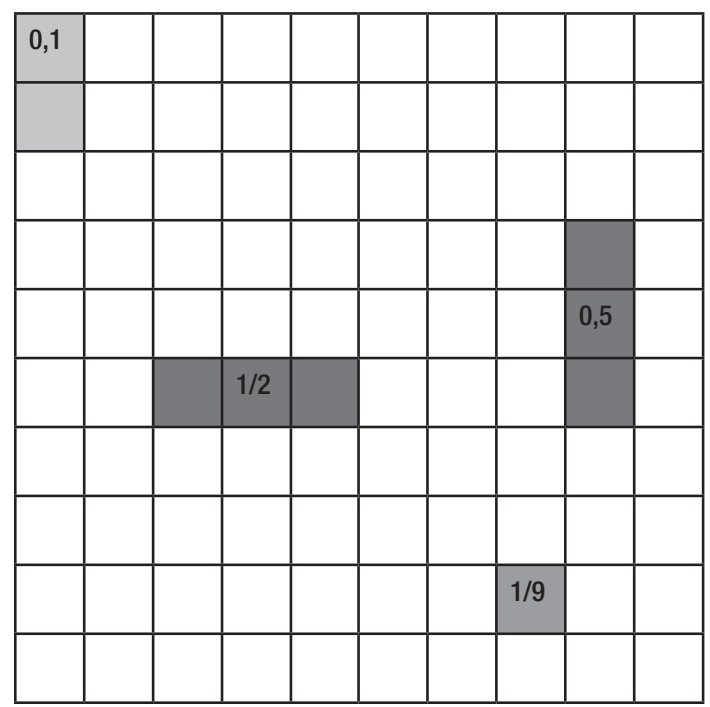

Figura 2 - Construção da unidade.

Nessa situação, é importante fornecer aos alunos as mesmas partes da unidade, mas em diferentes posições, e indicá-las recorrendo a diferentes representações (decimal e fracção), de modo que eles percebam claramente que, apesar de as partes diferirem em posição e representação, a quantidade é a mesma e que uma unidade pode possuir várias representações (à semelhança do que acontece na geometria, por exemplo, no caso dos triângulos, que são sempre triângulos, independentemente da posição em que os coloquemos). É importante também incentivar os alunos a discutirem entre si as diferentes representações da unidade que cada

3- Adaptado do trabalho de Monteiro et al. (2006). 
um encontrou, bem como as equivalências verificadas entre estas (ou outras).

Esse trabalho com os números fraccionários, em que necessariamente estão incluídos os decimais, deve representar uma ampliação dos conhecimentos dos alunos sobre os números e sobre o sistema numérico.

Quando pretendemos abordar as fracções e os decimais, podemos fazê-lo conjuntamente ou de forma isolada. Considero que essa abordagem deverá ser efectuada de modo conjunto, de maneira a explorar as relações existentes entre ambos e a permitir que os alunos construam e se apropriem dos conceitos de ordem e de equivalência entre eles, bem como das equivalências entre representações.

De modo a facilitar a aprendizagem, a construção de conhecimento e a aquisição do hábito de argumentar, devemos, como facilitadores das aprendizagens dos alunos, facultar-lhes a possibilidade de utilizarem materiais manipuláveis, modelos e situações do mundo real (por exemplo, o dinheiro, nomeadamente por meio de folhetos de supermercado, compra de bilhetes de transporte e de espectáculos etc.).

0 trabalho com fracções deverá ocorrer, preferencialmente, a partir de experiências de partilha equitativa, uma vez que o conceito de unidade e sua subdivisão em partes iguais é fundamental para compreender fracções e decimais (daí serem importantes as actividades com diferentes tipos de unidades). Essas actividades devem partir de situações quotidianas e de oralidade, reflectindo as situações modeladas (dividir seis sacos de rebuçados por quatro alunos, ou saber que parte de uma pizza come cada um dos quatro alunos). Para que as actividades sejam efectivamente profícuas, matematicamente desafiadoras e permitam aos alunos uma construção de conhecimento significativo sobre o tema, é necessário também que o professor possua um CME, em particular, sobre diferentes significados que podem assumir as fracções (parte-todo; operador; quociente; medida e coordenada linear) e sobre diferentes formas de representá-las.

Os números decimais devem surgir em contexto, devendo, portanto, ser associados a situações do dia a dia. Medir, comparar e ordenar comprimentos, pesos, quantidades e quantias de dinheiro em contextos práticos da vida de todos os dias permite descobrir naturalmente as relações de base entre os números decimais e entre estes e os inteiros.

Todos esses tipos de exploração e construção de conhecimentos por parte dos alunos apenas serão possíveis se o professor sentir-se suficientemente à vontade em seu papel, e se ele conseguir efectuar uma eficaz escolha e transposição entre os diversos tipos de representação a serem utilizados quando pretende abordar cada um dos conteúdos/temas do currículo. Essa escolha e exploração das representações está também intrinsecamente relacionada com a selecção das tarefas e com a forma como estas são exploradas, pois sua exigência cognitiva pode variar desde o momento em que as tarefas são seleccionadas/preparadas e durante o processo de instrução (STEIN et al., 2009). Mais uma vez, também a manutenção de um elevado nível de exigência cognitiva, que permita elaborar e manter as tarefas matematicamente desafiadoras, relaciona-se com o conhecimento matemático para ensinar que o professor possui relativamente ao tema que pretende abordar.

\section{Operações com decimais}

Ao mesmo tempo em que tomam contacto com as fracções/números decimais, os alunos começam, intuitivamente, a efectuar operações envolvendo-os. Antes ainda da aprendizagem formal das operações (independentemente do tipo de números que envolvam), os alunos devem tomar contacto 
com uma grande variedade de problemas que lhes permitam apreender as operações de modo informal, para que depois estas façam efectivamente sentido.

Desde cedo aprendemos as quatro operações básicas. Quando bebés, sabemos associar acções, como o choro e a birra, para conseguir determinado objectivo; aprendemos também a partilhar atenções, carinhos, brinquedos e, à medida que ficamos mais velhos, deveres, responsabilidades, culpa etc. É frequente, quando se parte um brinquedo, ouvir-se dizer que em vez de um ficámos com muitos. Também por esse motivo e de forma integrada, uma vez que devemos aproveitar todas essas experiências dos alunos, pode ser efectuada, desde o pré-escolar, uma abordagem significativa a esses conteúdos (SEBASTIÃO; RIBEIRO, 2009).

Para efectuarmos operações com números inteiros ou fraccionários, podemos/devemos, de modo a dar sentido e fornecer um contexto às actividades, utilizar diversos modelos e materiais manipuláveis, alguns dos quais foram já utilizados (ou deveriam ter sido) para introduzir a décima, a centésima e a milésima, quer seja o modelo contínuo ou discreto, o rectangular, o circular ou outro.

É de salientar que os alunos devem expressar uma mesma quantidade de diferentes formas, não se limitando a representação de um valor a uma única maneira, mas permitindo uma expansão de conhecimentos e saberes. Essa expansão leva a uma apropriação das equivalências existentes entre quantidades e, cumulativamente, das expressões, o que contribuirá também, posteriormente, para um mais rico e completo entendimento das relações e representações algébricas. Para representar uma mesma quantidade, portanto, devemos utilizar simultaneamente números decimais e números fraccionários bem como diferentes representações icónicas.

0 professor deve trabalhar a correspondência entre as diferentes representações nos dois sentidos: do número fraccionário para o número decimal e vice-versa. Os diferentes recursos devem permitir que se efectue uma clara comunicação entre as representações, sendo que, para isso, é necessário que o professor possua um sólido/rico e fundamentado CME. Apenas quando se possui tal conhecimento é possivel tornar compreensível para os alunos as diferentes equivalências e as distintas formas e significados que pode assumir determinado valor fraccionário. Os professores - actuais ou futuros - possuem um conhecimento limitado sobre o tema (e.g. DAMICO, 2007; RIBEIR0, 2009), motivo pelo qual esse deveria ser um dos aspectos a ser levado mais em conta em sua formação (inicial e contínua), discutindo o CME envolvido, pois apenas assim se poderá almejar tornar realidade uma verdadeira compreensão, por parte dos alunos, de toda a panóplia de formas de encarar os números decimais/fraccionários e suas operações.

\section{Operações, representações e importância do conhecimento matemático para ensinar}

Um aspecto fundamental quando abordamos as operações entre decimais (e, de uma forma geral, em todos os conteúdos), e para que seja possivel que os alunos as passem a efectuar com verdadeira compreensão, refere-se ao tipo de explorações com que estes são confrontados e ao entendimento que obtêm dessas explorações, assumindo as opções do professor em utilizar determinadas representações.

De seguida, apresento algumas representações passíveis de serem utilizadas na abordagem às operações com decimais (focando essencialmente a multiplicação), discutindo essas representações (e suas potencialidades) e abordando o CME que o professor necessita possuir, em concreto no que se refere à escolha e à circulação entre diversas representações para tornar essa perspectiva realidade. 


\section{Adição e subtracção de números decimais}

Sendo consideradas as mais simples, a adição e a subtracção são as mais importantes operações, uma vez que são a base para as restantes. Ainda assim, há que se ter em conta que a subtracção envolve um maior nível de complexidade (KAMMI; LEWIS; KIRKLAND, 2001). A abordagem às operações deverá ser efectuada utilizando não apenas os registos escritos, mas também modelos e materiais manipuláveis, sendo sua utilização predominante quando se abordam essas operações envolvendo números fraccionários.

É assim fundamental que, antes de abordarem as operações com decimais, os alunos já consigam navegar entre diversas das diferentes possíveis representações e formas de efectuar as operações (e.g. adições sucessivas, modelo rectangular ou o que denomino de modelo cartesiano contínuo). Se esses (ou outros) modelos já forem conhecidos dos alunos, quando do trabalho desenvolvido relativamen- te à multiplicação de números inteiros, tornar-se-á um importante contributo para uma verdadeira compreensão dos processos utilizados (tanto na primeira, como nessa situação), bem como das justificações. Essa compreensão leva a que não continuem a encarar a matemática como um conjunto de regras e procedimentos que se efectuam mecanicamente e sem qualquer relação com o quotidiano, e nos quais a utilização dos recursos é muito engraçada, mas não tem qualquer utilidade prática no que concerne à construção de conhecimento matemático compreensivo.

A utilização do material multibásico (MAB) é pertinente, pois permite que uma mesma peça possa representar diferentes quantidades, bastando para tal variar a unidade considerada, o que pode contribuir também para que os alunos deixem de encarar a matemática como algo estático (que lhes é apresentado na forma final), mas passem a encará-la como algo em construção e para o qual eles podem contribuir (ao seu nível, obviamente).

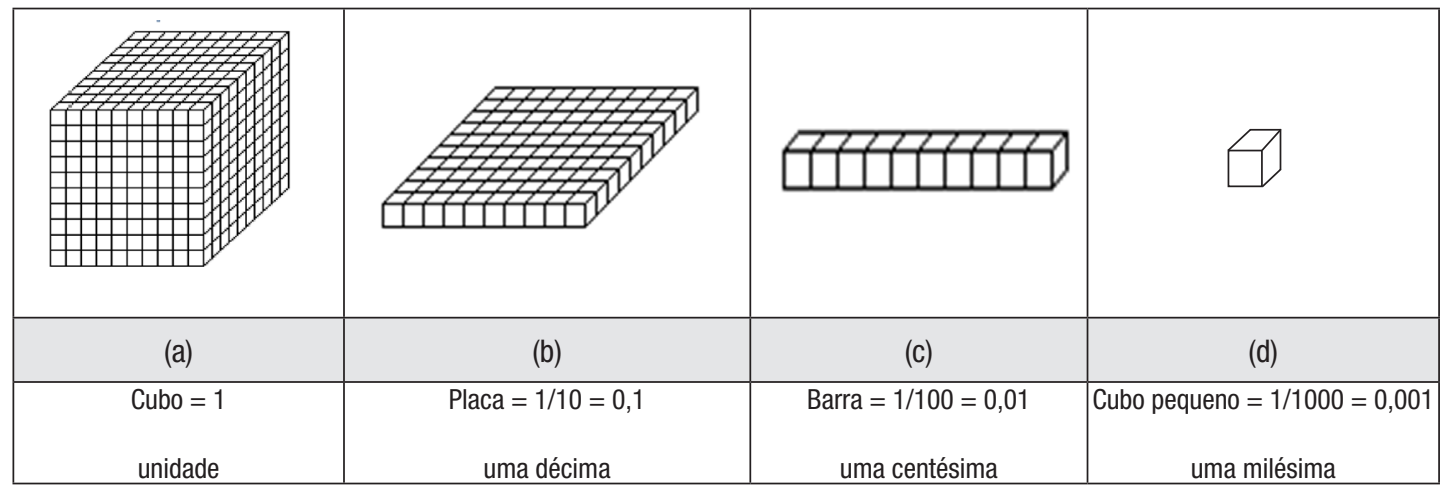

Figura 3 - Constituição do material multibásico (MAB).

Com esse tipo de material, considerando, por exemplo, o cubo grande (a) como a unidade, uma placa (b) é uma décima, uma barra (c) é uma centésima e um cubo pequeno (d) é uma milésima. Mas, alterando a unidade, considerando a placa a unidade, cada barra passa a ser uma décima e cada cubo pequeno uma centésima, sendo o cubo gran- de a dezena. É importante utilizar suas diferentes componentes como diferentes unidades, também para que os alunos se possam consciencializar da importância da escolha da unidade. (Esse tipo de conhecimento das possíveis relações entre os elementos constituintes do MAB é também útil para ordenar números decimais.) 
Tais ligações (navegação) entre as distintas formas de representar uma mesma situação possibilitarão um mais completo entendimento, por parte dos alunos, do algoritmo em si (e das possíveis distintas formas de encarar a subtracção), proporcionando sua efetuação com efectiva compreensão. No entanto, para que isso se efective, é fulcral que o professor seja detentor de um conhecimento - no sentido do CME - que lhe permita, entre outras coisas, utilizar uma linguagem matematicamente correcta e adequada ao nível de seus alunos e compreender os possíveis motivos subjacentes às dificuldades destes em entenderem, por exemplo, que a utilização quotidiana da expressão pedir emprestado não corresponde exactamente ao que se faz ao recorrer ao algoritmo tradicional (e da forma tradicional) para efectuar uma subtracção, e que daí podem surgir dificuldades de compreensão da operação.

É de salientar que frequentemente os alunos revelam algumas dificuldades em modelar (correctamente) a subtracção utilizando a forma retirar, pois, apesar de o fazerem nos registos escritos, na modelação efectuam a subtracção completando. Essas dificuldades em modelar as situações retirando uma quantidade de outra e a opção por fazê-lo recorrendo à operação inversa (completando com a quantidade que falta à menor para obter a maior) advêm (poderão advir) do facto de não ser possível agora, com recurso ao material manipulável, representar o pedir emprestado; daí que optem por completar para determinar a quantidade em falta e igualar ambas as quantidades iniciais. Para que possa ocorrer uma transposição automática entre essas formas de representação, portanto, é essencial que os alunos sejam confrontados com situações que lhes promovam a capacidade/ competência de reescrever inteligentemente determinada quantidade (desenvolver o sentido do número), assumindo essa competência como algo central em matemática, cumprindo aos alunos (e, por consequência inversa, aos professores) encarar essa reescrita como hábito e prática matemática.

\section{Multiplicação de números decimais}

Essa é, em geral, a operação em que os alunos demonstram maiores dificuldades (em paralelo com a divisão), pelo que a forma de encará-la e explorá-la com compreensão deverá passar a ser um dos focos de ensino (e da formação de professores). Dos muitos recursos possíveis de utilizar, o multibásico é talvez o mais indicado para uma abordagem introdutória também a essas operações envolvendo números decimais. Podemos ainda utilizar, paralelamente, o modelo rectangular e o modelo cartesiano (contínuo), de modo que os alunos possam efectuar o paralelismo entre esses, bem como a representação escrita (algoritmos), permitindo-lhes, posteriormente, abstrair-se com maior facilidade, sem a utilização dos recursos. Assim, nesse sentido, é importante que os alunos atribuam significado (sem efectuar o cálculo) a expressões/situações como: (a) a décima parte da décima é a centésima $(0,1 \times 0,1)$; (b) dez vezes uma centésima são dez centésimas, logo, é uma décima $(10 \times 0,01)$; (c) a centésima parte de dez unidades é uma décima $(0,01 \times 10)$; e (d) se dividir as dez unidades em cem partes iguais, ou seja, cada unidade dividida em dez partes iguais, cada uma dessas partes será uma décima.

Uma das grandes dificuldades dos alunos é a de perceberem por que motivo, ao multiplicarem duas determinadas quantidade de décimas, vão obter determinada quantidade de centésimas, ou seja, por que motivo, ao multiplicarem décimas por décimas, utilizando o algoritmo, têm de considerar duas e não apenas uma casa decimal (similarmente ao que efectuavam na adição e na subtracção). Essa dificuldade advém também das próprias dificuldades dos professores, em explicarem tal facto (RIBEIR0, 2009) pois, apesar de saberem-no para 
si próprios (na óptica do utilizador - conhecimento comum do conteúdo), não possuem um conhecimento de e sobre a matemática que lhes permita conhecer um conjunto distinto de propriedades relativas aos conteúdos específicos que pretendem ensinar, assim como formas distintas de fazê-lo - conhecimento especializado do conteúdo (BALL; THAMES; PHELPS, 2008; DELANEY et al., 2008; RIBEIR0, 2009).

Uma das possíveis formas de colmatar essa dificuldade sentida pelos alunos é abordar a multiplicação utilizando diferentes representações, sendo fundamental, para isso, que o professor possua um CME que lhe permita seleccionar e navegar, de forma compreensível e significativa para os alunos, entre essas representações.

Vejamos as representações que maiores e mais profícuas discussões e reflexões provocaram no grupo de trabalho; a partir delas, poderemos atribuir significado à multiplicação envolvendo decimais, pois permitem aos alunos (e aos professores) encontrar uma justificação para o facto de o número de casas decimais do produto corresponder à soma do número de casas decimais dos factores. Ao multiplicarmos números decimais, a menos de uma comutação, três situações podem ocorrer: (a) multiplicação de um número decimal por um inteiro; (b) multiplicação de um número decimal por um decimal superior à unidade; e (c) multiplicação de dois números decimais inferiores à unidade.

Por uma questão de simplicidade, considero, aqui, apenas valores em décimas. Não discutirei, de forma aprofundada, o papel e a importância da escolha dos exemplos seleccionados, porém, não posso deixar de salientar que esta é também uma importante componente a ter em conta quando se preparam as actividades, pois dessa escolha poderá depender a riqueza de toda a tarefa a ser proposta (MARTINS; RIBEIRO, 2009). (a) Multiplicação de um número decimal por um número inteiro

Para calcular $0,4 \times 2$, temos de dividir duas unidades (placas do MAB ou modelo quadrangular) em dez partes iguais, sendo, cada uma delas, dez partes equivalentes a duas décimas. Juntando quatro das dez partes, obtemos as oito décimas. (Os alunos efectuam, frequentemente, numa fase inicial, a adição $0,4+0,4$.)

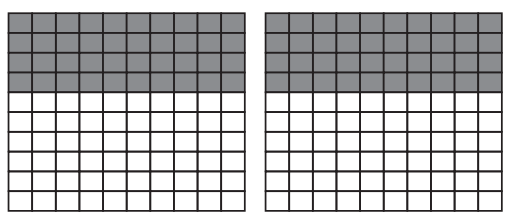

Assim, representando a quantidade em relação à unidade,

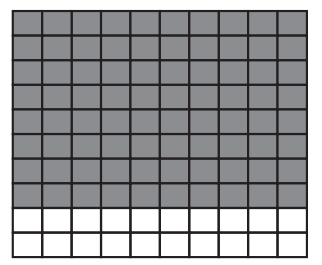

(b) Multiplicação de um número decimal por um número decimal superior à unidade

Se pretendermos calcular $0,7 \times 1,5$, que são sete décimas de uma unidade e meia, temos de dividir a unidade e meia - 15 décimas - em dez partes iguais, obtendo, desse modo, uma barra e meia em cada grupo (que passou agora a ser a décima parte do nosso conjunto). Como queremos quatro décimas (da unidade e meia), obtemos seis barras, que correspondem a $0,7 \times 1,5=0,85$.

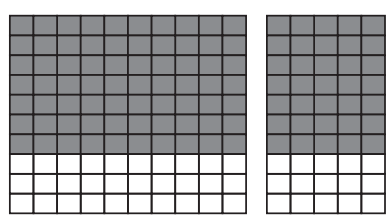


Ou seja, representando a quantidade em relação à unidade:

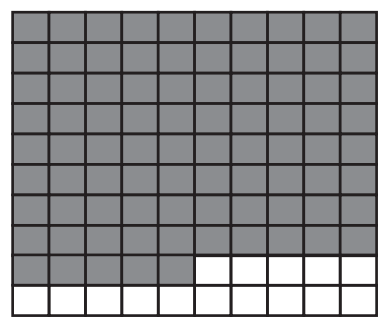

Outro processo frequentemente utilizado pelos alunos (nas turmas dos professores do grupo de trabalho) foi o de decompor $1,5 \mathrm{em} 1+1 / 2 \mathrm{de}$ 0,7 e fazer $0,7+0,7 \div 2=0,85$ (utilizando o MAB).

\section{(c) Multiplicação de dois números decimais inferio- res à unidade}

Essa é a situação: maiores exigências implicam em que os alunos possam efectuar a operação, utilizando o(s) algoritmo(s) com verdadeira compreensão e não apenas como um conjunto de regras que devem ser aplicadas. Se anteriormente já tiverem abordado a multiplicação recorrendo a diversas representações distintas, essa exigência será, assim, diminuta. Consideramos que pretendemos calcular 0,7 x 0,5.

Assumindo uma interpretação da multiplicação como área, para obter a representação resultante é necessário dividir cada um dos lados do rectângulo em dez partes iguais (aqui apenas estou a referir-me a décimas - o mesmo tipo de raciocínio pode ser aplicado na situação (b)).

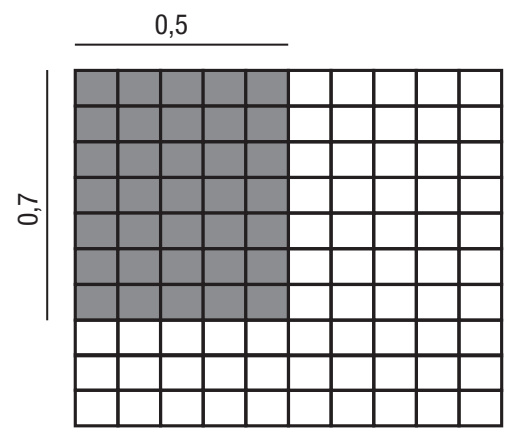

Outra forma de encarar a multiplicação é como produto cartesiano, e, para isso, podemos pintar de cores distintas a parte correspondente a cada um dos valores (depois de termos dividido as dimensões do rectângulo em dez partes iguais). 0 produto resultante é, nessa situação, a intersecção dos dois conjuntos, assumindo aqui que essa intercepção corresponde aos pares ordenados (contínuos) - de modo similar ao que pode ser efectuado quando pretendemos saber de quantas formas distintas nos podemos vestir com duas calças e três camisas diferentes (mas, nesse caso, é utilizado o modelo cartesiano discreto). Assim, a parte duplamente pintada corresponde à resposta à situação proposta. Note-se que uma parte importante do CME envolvido no recurso a esse tipo de representação refere-se a saber as razões que conduzem a que, para que se possa utilizar essa representação, multiplicando e multiplicador têm de ser representados (pintados) em direcções perpendiculares.

0,5

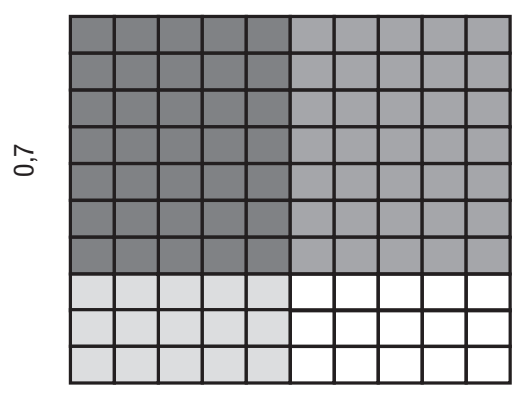

Esses processos de resolução (representações utilizadas) poderão ser aplicados de modo a esclarecer e clarificar uma das dúvidas frequentes dos alunos quando utilizam o algoritmo sem compreensão (o que também sustenta este artigo): por que motivo, ao multiplicarmos décimas por décimas, obtemos como resultado centésimas (temos de somar o número de casas decimais quando efectuamos uma multiplicação)? Mas para que ocorra uma 
efectiva compreensão do processo e do algoritmo (independentemente de qual é utilizado), é fundamental que o professor possua um CME que lhe permita não utilizar o material (as diferentes representações) apenas no sentido de ensinar os alunos a fazê-lo, mas de modo a dar-lhe significado, evidenciando as ligações que se podem estabelecer entre essas representações. Essa exploração, relacionada com o algoritmo, contribuirá para que os alunos compreendam, efectivamente, o que fazem quando aplicam o algoritmo numericamente.

\section{Algumas notas finais}

A realização desse tipo de tarefa, com o recurso a múltiplas representações (com sentido), promove nos alunos uma compreensão do que estão efectivamente a fazer, não aplicando somente uma regra para obter determinado resultado. Cabe-nos então, como professores, o papel de preparar tarefas que permitam ao aluno, durante o percurso de resolução, compreender efectivamente os processos por ele utilizados e transformar em aprendizagens com significado as experiências vivenciadas, não se limitando a repetir mecanicamente determinado conjunto de regras sem que lhe tenham algum significado.

0 facto de se abordarem conjuntamente as representações dos números em decimais e fraccionários possibilita que os alunos se consciencializem de diferentes representações para um mesmo valor, o mesmo ocorrendo quando se utilizam diversas quantidades como unidades discretas, ou distintos tipos de unidades.

As diversas representações apresentadas correspondem a situações que provocaram uma maior discussão no seio do grupo de trabalho, promovendo um aprofundamento do CME necessário nessas situações e do modo a navegar eficientemente entre os registos do algoritmo utilizado e as representações seleccionadas. Elas têm por objectivo ilustrar algumas das opções que podem ser realizadas com os alunos na introdução dos vários conceitos e são referidas com o intuito de que possam ser aplicadas em outro contexto, de modo a contribuir para uma melhoria dos conhecimentos dos alunos e a ajudá-los a fundamentar solidamente seus conhecimentos matemáticos.

Para que essas, ou quaisquer outras, propostas de trabalho/tarefas possam surtir o desejado efeito (ser matematicamente desafiadoras e promotoras de aprendizagens significativas), é fundamental que o professor seleccione adequadamente os exemplos com que trabalhar (e.g. MARTINS; RIBEIRO, 2009; R0WLAND, 2008), as representações que utiliza, bem como a forma como navega entre elas e como comunica com os (aos) alunos em cada uma dessas situações. Todas essas opções estão relacionadas com o CME (como tem sido argumentado) que o professor possui, pois ele é uma das dimensões fundamentais defınidoras de sua prática. De modo a que se torne realidade, em todas as salas de aula, uma prática direccionada para a verdadeira compreensão dos porquês e não apenas baseada na reprodução de estratégias/processos, é fundamental que ocorra uma perfeita navegação entre as diferentes representações seleccionadas e utilizadas pelos professores, devendo estas serem o mais ricas e diversificadas possível, pois, desse modo, estaremos a possibilitar aos alunos a criação de verdadeiras redes conceptuais.

É assim de sobeja importância que se passe a ter em efectiva conta, nos programas de formação de professores, esses aspectos/ dimensões, de modo a que se possam colmatar algumas das carências já identificadas em face do conhecimento dos professores (actuais ou futuros) em relação às possivveis formas de interpretar as fracções/números decimais (e.g. DAMIC0, 2007), formas estas que necessariamente também têm também relação com o tipo de exploração que passa a ser posteriormente efectuado nas operações envolvendo-os.

Com o intuito de que os alunos possam passar a dar sentido e significado à matemática 
escolar, em particular às operações envolvendo decimais ou fraccionários, é também fundamental que se tenha uma atenção cuidada à utilização de uma correcta linguagem matemática, de modo a permitir efectuar efectivas correspondências entre as diversas representações. É ainda de salientar a importância de como se consideram e utilizam os comentários dos alunos de modo a que se possa utilizar essa linguagem correcta. Esse aspecto corresponde a outra dimensão que faz parte do que assumo como conhecimento matemático para o ensino e encontra-se no mesmo nivel de todos as anteriores, uma vez que os alunos são a razão pela qual cada um de nós desenvolve sua acção docente.

\section{Referências}

BALL, D.; BASS, H. Toward a practice-based theory of mathematical knowledge for teaching. In: ANNUAL MEETING OF THE CANADIAN MATHEMATICS EDUCATION STUDY GROUP, 2002, Edmonton. Proceedings... Edmonton: CMESG/ GCEDM, 2003. p. 3-14.

BALL, D.; THAMES, M; PHELPS, G. Content knowledge for teaching: what makes it special? Journal of Teacher Education, v. 59, n. 5, p. 389-407, 2008.

BAROODY, A. J.; COSLICK, R. T. Fostering children's mathematical power: an investigative approach to k-8 mathematics instruction. Mahwah, NJ: Lawrence Erlbaum Associates, 1998.

DAMICO, A. Uma investigação sobre a formação inicial de professores de matemática para 0 ensino de números racionais no ensino fundamental. 2007. 313 p. Tese (Doutorado) - Pontifícia Universidade Católica de São Paulo, São Paulo, 2007.

DELANEY, S. et al. Mathematical knowledge for teaching: adapting U.S. measures for use in Ireland. Journal of Mathematics Teacher Education, v. 11, n. 3, p. 171-197, 2008.

DOERR, H. M.; ENGLISH, L. D. Middle grade teacher's learning through students engagement with modelling tasks. Journal of Mathematics Teacher Education, v. 9, p. 5-32, 2006.

HILL, H.; ROWAN, B.; BALL, D. Effects of teachers' mathematics knowledge for teaching on student achievement. American Education Research Journal, v. 42, n. 2, p. 371-406, 2005.

KAMMI, C.; LEWIS, B. E.; KIRKLAND, L. Fluency in subtraction compared with addition. Journal of Mathematical Behaviour, v. 20, p. 33-42, 2001.

LESH, R. et al. Principles for developing thoughts-revealing activities for students and teachers. In: LESH, R. A.; KELLY, A. (Eds.). Handbook of research design in mathematics and science education. Mahwah, $\mathrm{NJ}$ : Lawrence Erlbaum Associates, 2000. p. 591-646.

MARTINS, C.; RIBEIRO, C. M. Aprofundando o conhecimento matemático para ensinar: algumas situações no âmbito de um programa de formação contínua. In: ELEMENTARY MATHEMATICS EDUCATION, 3., 2008, Braga. Proceedings... Braga: Associação para a Educação Matemática Elementar e Universidade do Minho, 2009. p. 291-301.

MONTEIRO, C. et al. Cadeia de tarefas para o ensino dos decimais, 2006. (Documento não publicado).

PORTUGAL. Ministério da Educação. Departamento de Educação Básica (DEB). Currículo nacional do ensino básico: competências essenciais. Lisboa, 2001.

RIBEIRO, C. M. Práticas inclusivas em educação matemática: um trabalho colaborativo com professores do $1^{\circ}$ ciclo. In: BARCA, A. et al. (Eds.). Livro de Actas do Congreso Internacional Galego-Portugués de Psicopedagoxía. A Coruña/Universidade da Coruña: Revista Galego-Portuguesa de Psicoloxía e Educación, 2007. p. 1746-1757. 
Conhecimento matemático para ensinar: uma experiência de formação de professores no caso da multiplicação de decimais. Bolema, v. 22, n. 34, p. 1-26, 2009.

ROWLAND, T. The purpose, design and use of examples in the teaching of elementary mathematics. Educational Studies in Mathematics, v. 69, p. 149-163, 2008.

SEBASTIÃO, I.; RIBEIRO, C. M. Transversalidade da língua materna nas aprendizagens matemáticas em contexto pré-escolar. In: CONGRESSO INTERNACIONAL GALEGO-PORTUGUÊS DE PSICOPEDAGOGIA, 10., 2009, Braga. Actas... Braga: Universidade do Minho, 2009. p. 4701-4712.

SERRAZINA, L. et al. Programa de formação contínua em matemática para professores do $1^{\circ}$ ciclo, 2005. (documento não publicado). publicado).

Programa de formação contínua em matemática para professores do $1^{\circ}$ e $2^{\circ}$ ciclos, 2008. (documento não

STEIN, M. K. et al. Implementing standards-based mathematics instruction: a casebook for professional development. 2. ed. New York: Teachers College Press, 2009.

STREEFLAND, L. Fractions in realistic mathematics education: a paradigm of developmental research. Dordrecht: Kluwer Academic Publishers, 1991.

. Charming fractions or fractions being charmed? In: NUNES, T.; BRYANT, P. (Eds.). Learning and teaching mathematics: an international perspective. Hove: Psychology Press, 1997. p. 347-371.

Recebido em 17.03.10

Aprovado em 10.10.10

Carlos Miguel Ribeiro é docente da Universidade do Algarve (Portugal) e membro do Centro de Investigação sobre o Espaço e as Organizações (CIEO). Tem desenvolvido trabalhos na formação (inicial e contínua) de professores dos primeiros anos, com foco sobre a atenção no professor e no papel desempenhado por algumas das dimensões de seu conhecimento profissional na e para a prática. Aborda, entre outros temas, o conhecimento matemático para 0 ensino, a reflexão, a comunicação matemática e o trabalho colaborativo. 